\title{
THE CORRELATION BETWEEN NT Pro-BNP LEVELS AND ECHOCARDIOGRAPHIC FINDINGS IN A PATIENT WITH ACUTE ONSET DYSPNEA.
}

Sonal Virani, Pavan Kumar. M, Sunil Dalvi

\author{
1. Assistant Professor, Department of General Medicine, M. S. Ramaiah Medical College and Teaching \\ Hospital, Bangalore. \\ 2. Assistant Professor, Department of General Medicine, M. S. Ramaiah Medical College and Teaching \\ Hospital, Bangalore. \\ 3. Professor, Department of General Medicine, Lilavati, Mumbai.
}

\section{CORRESPONDING AUTHOR}

Dr. Pavan Kumar M, MD (Int-Med)

S/O H. A. Muniraja, No. 573,

Sri Maruthi Mansion, Chikkajala Post,

BB Road, Bangalore North - 562157

E-mail: pkapr13@gmail.com,

Ph: $00919449240254,00919964777846$.

ABSTRACT: BACKGROUND: Cardiac failure is one of the most serious and life threatening condition which needs an early diagnosis and prompt management to avoid mortality. 2 D echo serves as a very important tool in confirming the diagnosis of cardiac failure. Many centers in our country still don't have the facility of the same and hence we studied the role of NT pro-BNP as a substitute for $2 \mathrm{D}$ echo. AIM: The aim of this study was to compare the level of serum NT pro-BNP with the $2 \mathrm{D}$ echo findings in patients with acute onset dyspnea. METHODS: We studied 100 patients with acute onset dyspnea. Through history and examination was done. $2 \mathrm{~d}$ echo was done in all the patients. We measured the baseline level of serum NT Pro BNP in all the patients and a cut off level of $1800 \mathrm{pg} / \mathrm{ml}$ was kept to compensate for the caveats in the measurement of NT ProBNP. The personnel who did echo were blinded to the result of NT proBNP . We compared the $2 \mathrm{D}$ echo findings of the patients with the levels of NT pro-BNP. RESULTS: The ejection fraction, regional wall motion abnormality and diastolic dysfunction had significant correlation with a positive NT-ProBNP level, where as ventricular hypertrophy and pulmonary artery systolic pressure had no correlation with the same. CONCLUSIONS: NT proBNP level can be used to confirm the diagnosis of cardiac failure state in absence of $2 \mathrm{D}$ echo facilities.

KEY WORDS: Cardiac failure, NT Pro BNP, 2 D echo, diagnosis

INTRODUCTION: Heart failure is amongst the most common cause of acute onset dyspnoea. It is a clinical syndrome resulting from the inability of the heart to pump adequate amount of blood to meet the demands of the body. Main causes include coronary artery disease, hypertension, and complications of diabetes mellitus and anemia. The important precipitating factors include chest infection, accelerated hypertension, acute renal failure and other metabolic derangements. The left ventricular injury due to these causes leads to left ventricular remodeling, reduced ejection fraction, arrhythmias and sudden cardiac death (1). Hence, it is very essential to establish the diagnosis of cardiac failure early in the course of the disease to prevent mortality and morbidity from this condition. Several investigations including X-ray chest and 2D Echo serve as a useful guide to distinguish between the causes of dyspnoea.

Journal of Evolution of Medical and Dental Sciences/Volume1/Issue5/November-2012Page-775 
Over a period of years, BNP-brain natriuretic peptide has gained a lot of attention due to its high negative predictive value in dyspnoea of cardiac origin. The suspicion that the heart may have an endocrine function was raised approximately 50 years ago. At that time it was shown that dilatation of cardiac atria produced natriuresis (2). Initially BNP was proposed as a simple diagnostic tool to aid in the clinical assessment of decompensated heart failure; studies have now shown that this hormone offers enormous diagnostic as well as prognostic information in a variety of settings including cardiomyopathy, congestive heart syndromes, ischemic heart disease and even pulmonary thromboembolism(3). The PRIDE study conducted by the Experta Medica Inc. concluded that "Increased NT-proBNP was the strongest independent predictor of a final diagnosis of acute congestive heart failure (4)".

One more study conducted by Résumés Mogelvang et al at Copenhagen Denmark concluded that -In general population with dyspnoea, plasma pro-BNP concentration are increased in left ventricular dilatation, hypertrophy, systolic dysfunction or diastolic dysfunction but are unaffected by pulmonary dysfunction(5).

The main aim of our study was to establish the correlation between the serum level of NT pro-BNP and $2 \mathrm{D}$ echo findings so as to establish its role as a good substitute in the settings where $2 \mathrm{D}$ echo is unavailable.

\section{MATERIALS AND METHODS:}

- This is a prospective study of 100 patients with acute onset breathlessness for three years. Indoor patients admitted to Emergency Room and/ or intensive care unit of tertiary centre were taken as a trial population. Patients with acute onset dyspnea between 18-75 yrs both male and female were included. Patients with or without prior history of cardiac failure and on anti cardiac failure measures were taken. Patients presenting with acute onset dyspnea due to traumatic causes, known renal dysfunction or on dialysis of any form and with serum Creatinine $>2 \mathrm{mg} / \mathrm{dl}$ on day one of presentation were excluded.

This prospective analysis involved 100 patient presented to Lilavati hospital and research centre, a tertiary care centre with acute onset dyspnea. In all the patients taken, an initial history and through physical examination was done. The patients selected for the study were those who on first presentation to the emergency department needed intensive care support. The patients underwent routine blood investigations like complete blood count, liver profile, renal profile, x-ray chest, and electrocardiogram. The personnel doing the echocardiography were blinded to the result of NT-pro BNP. An echocardiography, cardiac troponin T, and NTpro BNP levels were measured in all the patients on presentation.

\section{NT-PROBNP ASSAY:}

- Elecsys pro BNP kit was used. It detects two polyclonal antibodies directed against NT-proBNP amino acid 1-21 and amino acid 39-50 respectively.

- NT-proBNP level was measured in heparinised serum sample of 20 microlitre.

- The test principle is Electrochemiluminescence sandwich immunoassay.

- It measures the level between $5-35,000 \mathrm{pg} / \mathrm{ml}$

- A cross reactivity of $0.001 \%$ with ANP, BNP and CNP 
The cut-off value to be considered significant in a given patient was kept $1800 \mathrm{pg} / \mathrm{ml}$ to compensate for the fluctuation in the NT-proBNP level with respect to age, gender, body mass index, previous history of heart failure etc. The patients were divided into positive and negative groups based on this cut-off level.

The levels of NT pro-BNP were compared with the 2D echo findings and all the data collected was analyzed statistically using chi- square tests which includes the Pearson chisquare, continuity correction and fisher's exact test. A p value was calculated using these tests. The association between all the parameters with the positive and the negative value was made and conclusions were drawn accordingly.

OBSERVATION AND RESULTS: A total of 100 patients of acute onset breathlessness presenting to ER of Lilavati hospital were studied. Out of these, 43 were females and 57 were males. The average age was 56.64 yrs with minimum being 18 and maximum being 75 years.

Amongst the 100 patients, 87 patients had an abnormal ECG and 52 had pulmonary edema on X-ray chest. 2D-echocardiography showed ejection fraction of less than $40 \%$ in 43 patients, diastolic dysfunction in 46 patients, regional wall motion abnormality in 41 patients, PASP of $>25 \mathrm{mmhg}$ in 39 patients and ventricular hypertrophy in 40 patients. A cardiac troponin T level of $>0.01$ was seen in 33 cases. (Figure: 1 )

NT- Pro BNP test was performed in all patients and showed a positive result $(>1800 \mathrm{pg} / \mathrm{ml})$ in $49 \%$ patients with a negative result in $51 \%$ (figure 2 ).

The $2 \mathrm{D}$ echo findings had a significant correlation with the positive result. The ejection fraction, regional wall motion abnormality and diastolic dysfunction had significant correlation with a positive NT-ProBNP level, where as ventricular hypertrophy and pulmonary artery systolic pressure had no correlation with the same. (Table1,2,3,4,5)

DISCUSSION: Cardiac failure is a burgeoning problem worldwide, with more than 20 million people affected. It is a clinical syndrome that occurs in patients who, because of an inherited or acquired abnormality of cardiac structure and or function, develop constellation of clinical symptoms (dyspnoea and fatigue) and signs (edema and rales) that lead to frequent hospitalization, a poor quality of life and shortened life expectancy (6). When confronted with a patient of acute onset dyspnoea in the emergency setting, a quick decision has to be made regarding the diagnosis of the cause. Heart failure (HF) is one of the most common causes. Patients with this syndrome often have co morbidities that contribute to their symptoms, thereby making the diagnosis difficult (7). Delays in diagnosing HF result in increased mortality, hospital stays, and treatment costs $(8,9)$. However, prompt evaluation of cardiac function with imaging such as nuclear scans and cardiac catheterization is not feasible in most settings. Furthermore, echocardiography, if available, can miss HF of diastolic origin(10) Given the increasing burden of HF and the increased benefits of early goal directed therapy, physicians in acute care settings require an accurate diagnostic test that will allow them to rapidly determine whether or not HF is the cause of their patients' symptoms .Various pulmonary diseases and other causes mimicking acute heart failure makes it challenging for the emergency department physician to take a call on the same .The Brain natriuretic peptides have gained a lot of interest in the recent years as a promising diagnostic and prognostic tool in the setting of acute onset dyspnoea Initially it was proposed as a simple diagnostic tool to aid in the clinical assessment of 
decompensated heart failure; studies have now shown that this hormone now offers enormous diagnostic as well as prognostic information in a variety of settings including cardiomyopathy, congestive heart failure syndromes, ischemic heart disease and even pulmonary thromboembolism. The first study done was by David and colleagues who measured the levels of the natriuretic hormones ANP and BNP in 52 patients presenting with acute dyspnoea. They found that admission plasma BNP concentration more accurately reflected the final diagnosis than did left ventricular ejection fraction or ANP plasma concentration.(11)

The first use of the point-of-care BNP assay was used by Dao and colleagues who evaluated 250 patients presenting to an urgent care centre with the chief complaint of dyspnoea. The end result of the study was that BNP levels were the strongest predictor of those who had heart failure. (12) This particular finding spurred the international Breathing Not Properly study which was a large-scale prospective study using BNP levels to evaluate the cause of dyspnoea. This trail prospectively evaluated 1586 patients who presented to the ED with acute dyspnoea. A BNP cutoff value of $100 \mathrm{pg} / \mathrm{ml}$ had a sensitivity of $90 \%$ and a specificity of $76 \%$ for differentiating heart failure from other causes of dyspnoea . (13) A study on the lines of Breathing Not Properly trail was conducted using the NT pro-BNP level in patients with dyspnoea. The proBNP Investigation of Dyspnoea in the Emergency Department (PRIDE) study (4) evaluated 600 patients presenting to the ED with acute onset dyspnoea. NT-proBNP levels were compared with the clinical assessment of managing physicians for identifying CHF. The authors suggested two different, age-based cut-points for diagnosing acute heart failure: NT pro BNP above $450 \mathrm{pg} / \mathrm{ml}$ for those younger than 50 yrs old and NT-proBNP above $900 \mathrm{pg} / \mathrm{ml}$ for those 50 yrs or older. The study found that NT-proBNP was the strongest independent predictor of a final diagnosis of acute heart failure with an odds ratio of 44. The optimal cut-point for ruling out heart failure was NT-proBNP less than $300 \mathrm{pg} / \mathrm{ml}$, which had a 99\% negative predictive value. This study helped establish the clinical utility of NT-proBNP for diagnosing or excluding heart failure in the ED setting.

Another study done in the general population with dyspnoea concluded that plasma proBNP concentrations are increased in left ventricular dilatation, hypertrophy, systolic dysfunction, or diastolic dysfunction, but are unaffected by pulmonary dysfunction (5) The level of B-type natriuretic peptides is influenced by a many factors. These factors may play an important role in the discordance observed in the clinical picture and the given value of NTproBNP in the blood. (14) Previous history of heart failure often gives a natriuretic peptide value above the suggested cut-off points, even though the patient is evoluemic. To minimize this error, it is worth while having a base line value in such patients in their dry weight, any significant deviation from this value could then be used for either diagnosing acute exacerbation of heart failure or much lower value might indicate that the patient is over diurised. (13) The level of NT-pro BNP is much higher in the elderly age group as compared to the general population. Defining an age based cut-point for NT-proBNP has helped to over come this short coming. (14) The levels of natriuretic peptides have found to be higher in females as compared to males of the corresponding age. Studies have shown that estrogen might have a role to play in this; however these differences are unimportant while dealing with an acutely dyspneic patient. (15) The natriuretic peptides level rise with worsening renal function though it is unclear whether the concomitant heart disease with renal failure or decreased clearance of the hormone via the kidneys is responsible for this rise.

As there are factors which give a false high value, there are factors which give a value lower than normal despite clear presence of cardiac failure. The following conditions need to be 
kept in mind while dealing with a difference in the clinical scenario and the levels of NTproBNP. Obesity is one of the conditions which give rise to a lower value even in the presence of heart failure. The pathphysiologic base for this is still debated. There is some evidence that natriuretic peptide receptors in the adipose cells lead to increased clearance of the hormone, there may also be a component of reduced natriuretic peptide secretion in obesity that may also contribute to this low level. For patients with acute dyspnoea and a body mass index of more than 35, a cut-point of BNP $54 \mathrm{pg} / \mathrm{ml}$ or higher maintains the same $90 \%$ sensitivity for diagnosing acute CHF as does the standard cut-point of BNP $100 \mathrm{pg} / \mathrm{ml}$ or higher in non obese individuals. Flash pulmonary edema can give an in appropriately low level of the natriuretic peptide. This may be due to the time required for natriuretic peptide up-regulation and expression in response to ventricular wall stress. CHF resulting due o upstream from the left ventricle, such as acute mitral regurgitation or mitral stenosis, natriuretic peptide levels can be low or normal despite severe CHF. This is because the left ventricular function may be uncompromised, especially in the acute setting. On the similar lines, the patients with constrictive pericarditis may have symptoms of heart failure and elevated filling pressures, but tend to have low natriuretic peptide level due to lack of ventricular stretch.(14) A significant correlation between the higher levels of NT-proBNP and echocardiography findings makes it a good substitute for echocardiography in the setting of absence of trained personnel. The excellent correlation between the raised value and diastolic dysfunction helps in better diagnosis of the condition.

CONCLUSION: NT pro-BNP level can be used to confirm the diagnosis of cardiac failure state in absence of $2 \mathrm{D}$ echo facilities.

ACKNOWLEGEMENT: I thank Dr. Prakash Jiandani and Dr. Shashank Joshi for their constant support and guidance during the study.

\section{BIBLIOGRAPHY:}

1. Girish B Ramteke, Lincy G Ramteke, Current concepts in management of congestive heart failure. Postgraduate Medicine (Emergency medicine-Emerging Discipline) 2008 197-211.

2. Henry JP, Gauer $\mathrm{OH}$, Reeves JL. Evidence of the atrial location of receptors influencing urine flow. Circ Res 1956; 4:85 -90.

3. Jagat Narula, James B. Young editorial Natriuretic peptides in heart failure: Empathizing with the sobbing heart. Heart failure clinics July 2006 volume 2 xi-xiii

4. James L. Januzzi, Jr., The N-Terminal Pro-BNP Investigation of Dyspnea in the Emergency Department (PRIDE) Study

5. Rasmus Mogelvang, MD, Discriminating Between Cardiac and Pulmonary Dysfunction in the General Population with Dyspnoea by Plasma Pro-B-Type Natriuretic Peptide. Journal of the American College of Cardiology Vol. 50, No. 17, 2007 1694-701.

6. Douglas L. Mann Heart failure and cor pulmonale Harrison's principles of internal medicine 1433-45

7. Doust JA, Glasziou PP, Pietrzak E, Dobson AJ. A systematic review of the diagnostic accuracy of natriuretic peptides for heart failure. Arch Intern Med 2004; 164:1978-84. 
8. Bales AC, Sorrentino MJ. Causes of congestive heart failure. Prompt diagnosis may affect prognosis. Post grad Med 1997; 101:44-6.

9. Wuerz RC, Meador SA. Effects of pre hospital medications on mortality and length of stay in congestive heart failure. Ann Emerg Med 1992; 21:66974

10. Wang CS, FitzGerald JM, Schulzer M, Mak E, Ayas NT. Does this dyspneic patient in the emergency department have congestive heart failure? JAMA 2005; 294:1944-56.

11. Davis M, Epiner E, Richards G, et al. Plasma brain natriuretic peptide in assessment of acute dyspnea. Lancet 1994:343(8995):440-4

12. Dao Q, Krishnaswamy P, Kazanegra R, et al. Utility of B-type natriuretic peptide in the diagnosis of congestive heart failure in an urgent care setting. J am coll Cardiol 2001;37(2):379-85

13. Maisel AS, Krihnaswamy P, Nowak RM, et al. Rapid measurement of B-type natriuretic peptide in the emergency diagnosis of heart failure. New England Journal of Medicine 2002;347(3):161-7

14. Loris B. Daniels, MD, Alan S. Maisel, MD Natriuretic peptides as diagnostic test : Lessons from the first 5 years of clinical application Heart failure clinic 2 (2006) 299-309

15. Redfield MM, Rodeheffer RJ, Jacobsen SJ, et al. Plasma brain natriuretic peptide concentration: impact of age and gender. J Am Coll Cardiol 2002:40(5):976-82

Table no. 1: Association among the cases between- Ejection Fraction (\%) \& NT- Pro BNP $(\mathrm{pg} / \mathrm{ml})$

\begin{tabular}{|l|l|l|l|l|}
\hline \multirow{2}{*}{ Ejection Fraction (\%) } & & \multicolumn{2}{|l|}{ NT- Pro BNP (pg/ml) } & \multirow{2}{*}{ Total } \\
\cline { 3 - 4 } & & $\mathbf{>} \mathbf{1 8 0 0}$ & $<\mathbf{1 8 0 0}$ & \\
\hline \multirow{2}{*}{ Low } & No. & 34 & 9 & 43 \\
\cline { 2 - 5 } & $\mathbf{\%}$ & $79.1 \%$ & $20.9 \%$ & $100.0 \%$ \\
\hline \multirow{2}{*}{ Normal } & No. & 15 & 42 & 57 \\
\cline { 2 - 5 } & $\mathbf{\%}$ & $26.3 \%$ & $73.7 \%$ & $100.0 \%$ \\
\hline \multirow{2}{*}{ Total } & No. & 49 & 51 & 100 \\
\cline { 2 - 4 } & $\mathbf{\%}$ & $49.0 \%$ & $51.0 \%$ & $100.0 \%$ \\
\hline
\end{tabular}

\begin{tabular}{|l|l|l|l|l|}
\hline Chi-square tests & Value & df & p-value & Association is- \\
\hline Pearson Chi-Square & 27.2950 & 1 & $1.75 \mathrm{E}-07$ & Significant \\
\hline Continuity Correction & 25.225 & 1 & $5.10 \mathrm{E}-07$ & Significant \\
\hline Fisher's Exact Test & & & $2.30 \mathrm{E}-07$ & Significant \\
\hline
\end{tabular}


Table 2: Association among the cases between- Diastolic Dysfunction \& NT- Pro BNP $(\mathrm{pg} / \mathrm{ml})$

\begin{tabular}{|l|l|l|l|l|}
\hline \multirow{2}{*}{ Diastolic Dysfunction } & & \multicolumn{2}{|l|}{ NT- Pro BNP $(\mathbf{p g} / \mathbf{m l})$} & \multirow{2}{*}{ Total } \\
\cline { 3 - 5 } & & $\mathbf{>} \mathbf{1 8 0 0}$ & $<\mathbf{1 8 0 0}$ & \\
\hline \multirow{2}{*}{ Yes } & No. & 28 & 18 & 46 \\
\cline { 2 - 5 } & $\mathbf{\%}$ & $60.9 \%$ & $39.1 \%$ & $100.0 \%$ \\
\hline \multirow{2}{*}{ No } & No. & 21 & 33 & 54 \\
\cline { 2 - 5 } & $\mathbf{\%}$ & $38.9 \%$ & $61.1 \%$ & $100.0 \%$ \\
\hline \multirow{2}{*}{ Total } & No. & 49 & 51 & 100 \\
\cline { 2 - 5 } & $\mathbf{\%}$ & $49.0 \%$ & $51.0 \%$ & $100.0 \%$ \\
\hline
\end{tabular}

\begin{tabular}{|l|l|l|l|l|}
\hline Chi-square tests & Value & df & p-value & Association is- \\
\hline Pearson Chi-Square & 4.8030 & 1 & 0.028 & Significant \\
\hline Continuity Correction & 3.963 & 1 & 0.047 & Significant \\
\hline Fisher's Exact Test & & & 0.044 & Significant \\
\hline
\end{tabular}

Table 3: Association among the cases between- RVMA \& NT- Pro BNP (pg/ml)

\begin{tabular}{|c|c|c|c|c|}
\hline \multirow{2}{*}{ RVMA } & & \multicolumn{2}{|c|}{ NT- Pro BNP (pg/ml) } & \multirow{2}{*}{ Total } \\
\hline & & $>=1800$ & $<1800$ & \\
\hline \multirow[t]{2}{*}{ Yes } & No. & 32 & 9 & 41 \\
\hline & $\%$ & $78.0 \%$ & $22.0 \%$ & $100.0 \%$ \\
\hline \multirow[t]{2}{*}{ No } & No. & 17 & 42 & 59 \\
\hline & $\%$ & $28.8 \%$ & $71.2 \%$ & $100.0 \%$ \\
\hline \multirow[t]{2}{*}{ Total } & No. & 49 & 51 & 100 \\
\hline & $\%$ & $49.0 \%$ & $51.0 \%$ & $100.0 \%$ \\
\hline Chi-square tests & Value & df & p-value & Association is- \\
\hline Pearson Chi-Square & 23.4650 & 1 & $1.27 \mathrm{E}-06$ & Significant \\
\hline Continuity Correction & 21.536 & 1 & $3.47 \mathrm{E}-06$ & Significant \\
\hline Fisher's Exact Test & & & 1.79E-06 & Significant \\
\hline
\end{tabular}


Table 4: Association among the cases between- Ventricular Hypertrophy \&NT- Pro BNP (pg/ml)

\begin{tabular}{|c|c|c|c|c|}
\hline \multirow{2}{*}{ Ventricular Hypertrophy } & & \multicolumn{2}{|c|}{ NT-Pro BNP (pg/ml) } & \multirow{2}{*}{ Total } \\
\hline & & $>=1800$ & $<1800$ & \\
\hline \multirow[t]{2}{*}{ Yes } & No. & 24 & 16 & 40 \\
\hline & $\%$ & $60.0 \%$ & $40.0 \%$ & $100.0 \%$ \\
\hline \multirow[t]{2}{*}{ No } & No. & 25 & 35 & 60 \\
\hline & $\%$ & $41.7 \%$ & $58.3 \%$ & $100.0 \%$ \\
\hline \multirow[t]{2}{*}{ Total } & No. & 49 & 51 & 100 \\
\hline & $\%$ & $49.0 \%$ & $51.0 \%$ & $100.0 \%$ \\
\hline
\end{tabular}

\begin{tabular}{|l|l|l|l|l|}
\hline Chi-square tests & Value & df & p-value & Association is- \\
\hline Pearson Chi-Square & 3.2280 & 1 & 0.072 & Not significant \\
\hline Continuity Correction & 2.536 & 1 & 0.111 & Not significant \\
\hline Fisher's Exact Test & & & 0.102 & Not significant \\
\hline
\end{tabular}

Table 5: Association among the cases between- PSAP (mm Hg) \& NT- Pro BNP (pg/ml)

\begin{tabular}{|l|l|l|l|l|}
\hline \multirow{2}{*}{ PSAP (mm Hg) } & & \multicolumn{2}{|l|}{ NT- Pro BNP (pg/ml) } & \multirow{2}{*}{ Total } \\
\cline { 3 - 5 } & & $\mathbf{>}=\mathbf{1 8 0 0}$ & $<\mathbf{1 8 0 0}$ & \\
\hline \multirow{2}{*}{ Abnormal } & No. & 23 & 16 & 39 \\
\cline { 2 - 5 } & $\mathbf{\%}$ & $59.0 \%$ & $41.0 \%$ & $100.0 \%$ \\
\hline \multirow{2}{*}{ Normal } & No. & 26 & 35 & 61 \\
\cline { 2 - 5 } & $\mathbf{\%}$ & $42.6 \%$ & $57.4 \%$ & $100.0 \%$ \\
\hline \multirow{2}{*}{ Total } & No. & 49 & 51 & 100 \\
\cline { 2 - 5 } & $\mathbf{\%}$ & $49.0 \%$ & $51.0 \%$ & $100.0 \%$ \\
\hline
\end{tabular}

\begin{tabular}{|l|l|l|l|l|}
\hline Chi-square tests & Value & df & p-value & Association is- \\
\hline Pearson Chi-Square & 2.5450 & 1 & 0.111 & Not significant \\
\hline Continuity Correction & 1.933 & 1 & 0.164 & Not significant \\
\hline Fisher's Exact Test & & & 0.151 & Not significant \\
\hline
\end{tabular}



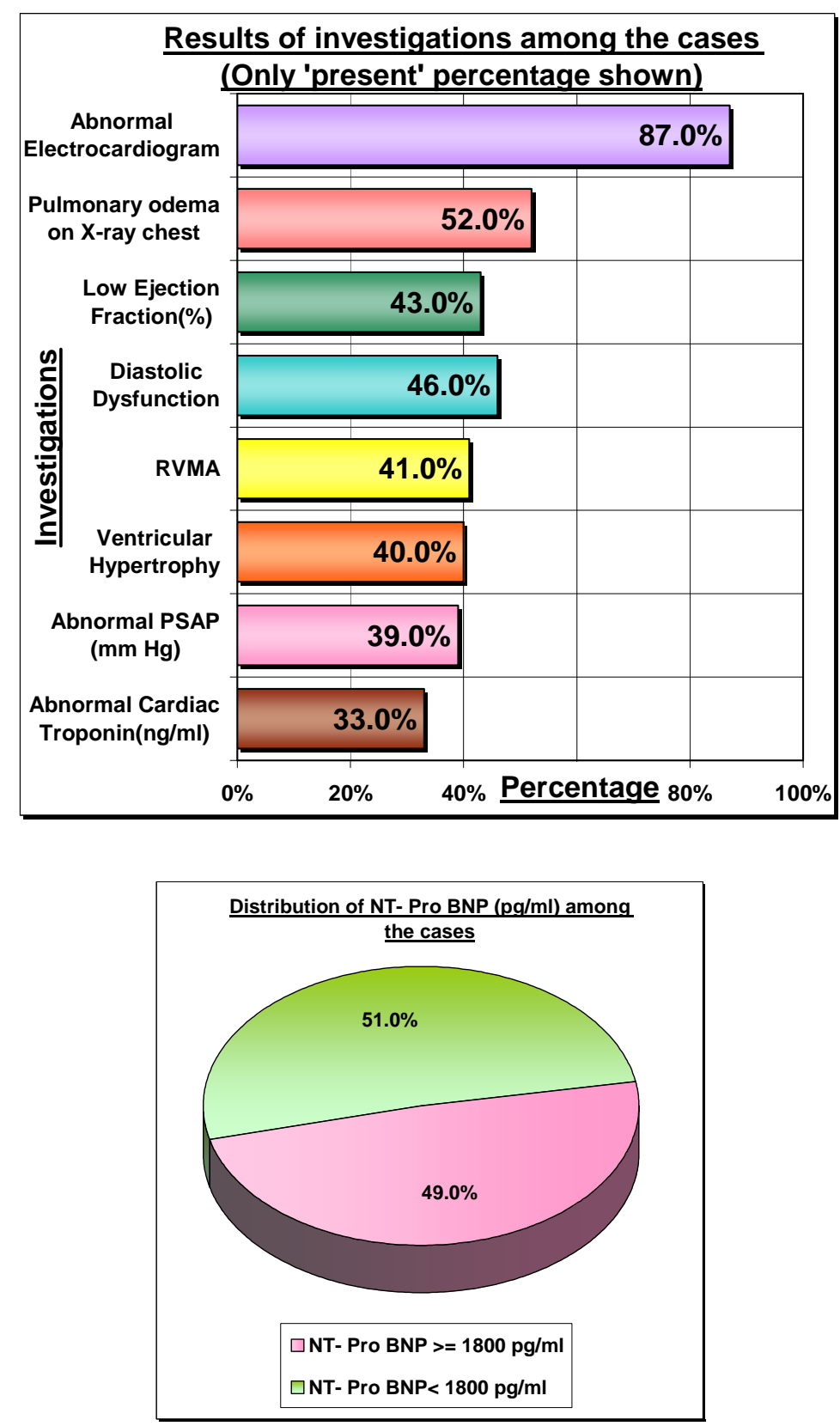

Fig: 2 NT- Pro BNP Test 